\title{
Porous Silica Nanotube Thin Films as Thermally Insulating Barrier Coatings
}

\author{
Derric B. Syme \\ Brigham Young University - Provo \\ Jason M. Lund \\ Brigham Young University - Provo \\ Brian D. Jensen \\ Brigham Young University - Provo \\ Robert C. Davis \\ Brigham Young University - Provo \\ Richard R. Vanfleet

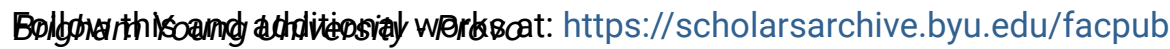 \\ Part of the Mechanical Engineering Commons
}

See next page for additional authors

Original Publication Citation

Syme, D. B., Lund, J. M., Jensen, B. D., Davis, R. C., Vanfleet, R. R., and Iverson, B. D., 2020, "Porous silica nanotube thin films as thermally insulating barrier coatings," ACS Applied Nano Materials, 3(4), pp. 3168-3173. DOI: 10.1021/acsanm.0c00596

\section{BYU ScholarsArchive Citation}

Syme, Derric B.; Lund, Jason M.; Jensen, Brian D.; Davis, Robert C.; Vanfleet, Richard R.; and Iverson, Brian D., "Porous Silica Nanotube Thin Films as Thermally Insulating Barrier Coatings" (2020). Faculty Publications. 5086.

https://scholarsarchive.byu.edu/facpub/5086

This Peer-Reviewed Article is brought to you for free and open access by BYU ScholarsArchive. It has been accepted for inclusion in Faculty Publications by an authorized administrator of BYU ScholarsArchive. For more information, please contact ellen_amatangelo@byu.edu. 


\section{Authors}

Derric B. Syme, Jason M. Lund, Brian D. Jensen, Robert C. Davis, Richard R. Vanfleet, and Brian D. Iverson 


\section{Porous Silica Nanotube Thin Films as Thermally Insulating Barrier Coatings}

Derric B. Syme, Jason M. Lund, Brian D. Jensen, Robert C. Davis, Richard R. Vanfleet, and Brian D. Iverson*

Cite This: ACS Appl. Nano Mater. 2020, 3, 3168-3173

Read Online

ABSTRACT: The fabrication and examination of a porous silica thin film, potentially for use as an insulating thin film, were investigated. A vertically aligned carbon nanotube (CNT) forest, created by chemical vapor deposition (CVD), was used as scaffolding to construct the porous film. Silicon was deposited on the CNT forest using low-pressure CVD (LPCVD) and then oxidized to remove the CNTs and convert the silicon to silica for electrical or thermal passivation (e.g., thermal barrier). Thermal conductivity was determined using a $1 \mathrm{D}$ heat-transfer analysis that equated radiative heat loss in a vacuum with conduction through the substrate and thin film stack. A comparison of the surface temperature differences between a sample film and a reference of

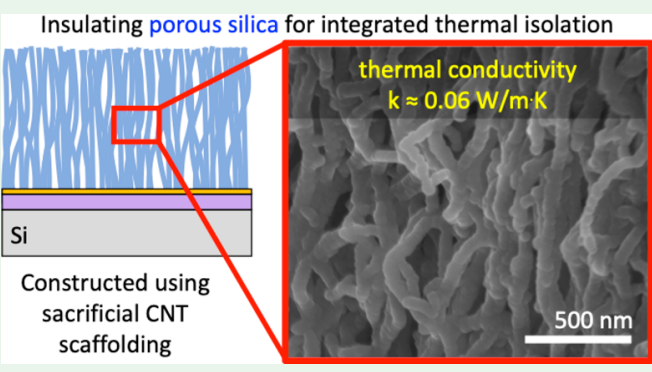
comparable thermal resistance enabled determination of the increase in the thermal resistance and of the thermal conductivity of the films. For film thicknesses of approximately $55 \mu \mathrm{m}$, the cross-plane thermal conductivity was found to be $0.054-0.071 \mathrm{~W}^{-1} \mathrm{~K}^{-1}$ over $378-422 \mathrm{~K}$. This thermal conductivity value is in the range of other silica aerogels and consistent with the low gravimetric density of $0.15 \mathrm{~g} \mathrm{~cm}^{-3}$ for the samples. The film is also relatively smooth and flat, with an average arithmetic mean roughness of 1.04 $\mu \mathrm{m}$.

KEYWORDS: silica, carbon nanotube, thin films, insulation, MEMS, thermal barrier, aerogel

$\mathrm{C}$ arbon nanotubes (CNTs) can achieve incredible lengthto-diameter ratios. With a diameter of just a few nanometers wide, practical length-to-diameter ratios can be greater than 10000:1, providing relatively large surface area with little volume. ${ }^{1,2}$ The thermophysical and geometric properties for CNTs make them attractive for constructing thin-film materials for use in thermal applications. Robust, high-aspect-ratio microstructures, including microscale films, have been fabricated in a process called CNT-templated microfabrication (CNT-M). ${ }^{3-6}$ In CNT-M, a patterned CNT forest acts as a scaffold, which is infiltrated or coated with additional materials. The conditions and duration of an infiltration procedure can be controlled to result in highly dense or highly porous forest regions. Control of the porosity of the structure and the ability to use insulating materials as scaffolding in a porous thin film makes CNT-M intriguing for use in the creation of a thermally or electrically insulating layer for a microelectromechanical system (MEMS) and other microscale sensors.

Traditional insulating materials in MEMS, such as silicon oxide or silicon nitride, while having a much lower thermal conductivity than silicon, have values larger than that required for many MEMS applications. Further, thermal or electrical cross-talk can affect the sensor sensitivity and accuracy. Attempts to incorporate other insulating materials, such as silica aerogels, into microdevices have failed to preserve the material's low thermal conductivity. ${ }^{7}$ Aerogels are lightweight, synthetic materials that can be fabricated from a variety of chemical compounds [including silica $\left(\mathrm{SiO}_{2}\right)^{8}$ ], but they generally lack structural integrity and do not have a clear path for MEMS integration. Recent explorations into using nanostructures to create spectrally selective surfaces for radiative cooling indicate promise in tailoring thermal and structural properties. ${ }^{9,10}$ Silica-based, porous materials constructed from nanoparticles have also appeared in recent literature, demonstrating low thermal conductivities of $0.10-$ $0.16 \mathrm{~W} \mathrm{~m}^{-1} \mathrm{~K}^{-1}$ using sol-gel methods to obtain free-standing silica monoliths. ${ }^{11}$

This work explores the capability of using insulating thin films, constructed using CNT-M, as a thermal barrier in MEMS sensors and similar applications by determining the thermal conductivity of porous silica nanotube thin films. CNT-M affords the method to create insulating thin films that can be integrated into MEMS/nanoelectromechanical system (NEMS) sensor architectures by infiltrating CNT forests with

Received: March 1, 2020

Accepted: March 19, 2020

Published: March 19, 2020 
(a)

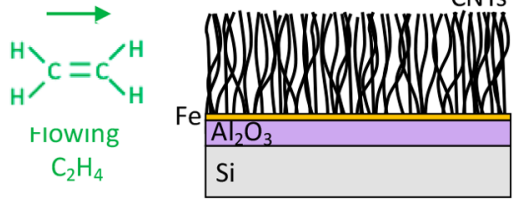

(b)

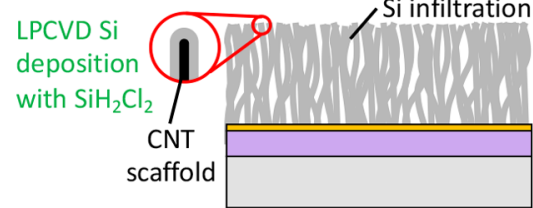

(c)

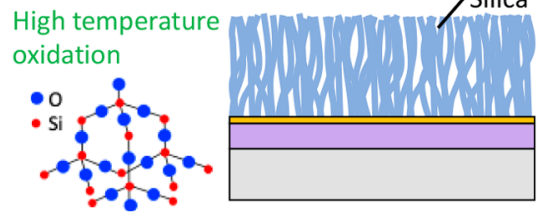

\section{(d)}

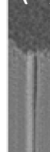

$40 \mu \mathrm{m}$

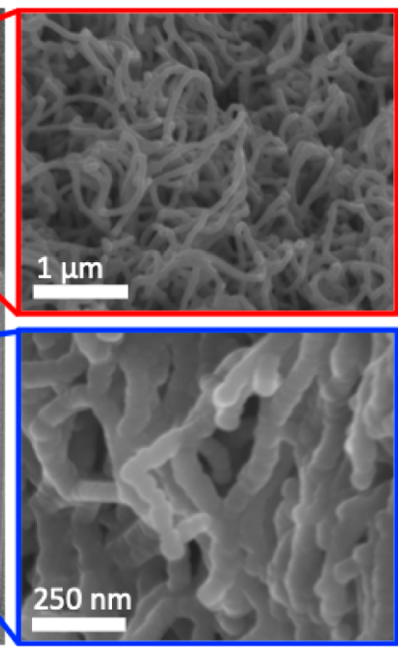

Figure 1. (a) Vertically aligned CNTs grown using a lithographically patterned catalyst. (b) Uniform silicon infiltration of the CNT forest using LPCVD. (c) Oxidation in an $\mathrm{O}_{2}$-rich furnace, burning away the CNTs and leaving a (d) porous silica structure.

low-pressure chemical vapor deposition (LPCVD) of silicon and then oxidizing at high temperatures to simultaneously burn out the carbon and oxidize the silicon. The result is a porous silica structure similar to an aerogel. However, a structure of this kind offers several specific benefits relative to aerogels. First, porous silica films in this work offer the ability to easily and preferentially locate insulating regions on a substrate through lithographic patterning or liftoff of the iron catalyst used for CNT growth. Second, control of the CNT growth height readily offers control of the film thickness (and associated thermal and electrical resistance); the terminal film thickness or CNT growth height is achieved in less than a 1 or 2 min (typically on the order of tens of seconds). Third, our approach offers a rigid, surface-mounted insulating layer. It is this flexibility in patterning and control of the dimensions that make this material particularly attractive, while also providing a low thermal conductivity. It is envisioned that these porous silica thin films may be used to isolate measurements that would otherwise require a suspended MEMS structure, as in the case of a thermal conductivity detector $^{12-14}$ or a microbolometer. ${ }^{15}$ Patterned silica structures of this kind have been demonstrated to be effective for use in chromatography. ${ }^{4}$ The current work demonstrates that structurally stable, insulating thin films can be created using CNT scaffolds to achieve a porous insulating material and seeks to quantify the cross-plane thermal conductivity.

Porous silica films were produced following the CNT-M procedure shown in Figure $1 \mathrm{a}-\mathrm{c}$ and procedures similar to those in previous CNT-templated works. ${ }^{4}$ Aluminum oxide (50 nm, e-beam evaporation) and iron (4 nm, thermal evaporation) were deposited onto a silicon wafer. CNTs were grown using a chemical vapor deposition (CVD) process of flowing ethylene $\left(\mathrm{C}_{2} \mathrm{H}_{4}\right)$ over an iron catalyst at elevated temperature. In a $2.54-\mathrm{cm}$-o.d. tube furnace, samples were brought to $750{ }^{\circ} \mathrm{C}$ in the presence of flowing hydrogen $\left(\mathrm{H}_{2}\right)$ at $310 \mathrm{sccm}$. At temperature and while still flowing $\mathrm{H}_{2}, 340 \mathrm{sccm}$ of ethylene was introduced for $50 \mathrm{~s}$, growing CNTs of 40-60 $\mu \mathrm{m}$ height (55 $\mu \mathrm{m}$ average). After growth, $\mathrm{H}_{2}$ and ethylene were turned off, and argon was flowed over the samples for 1 min. The furnace heating was then turned off, while argon continued to flow in order to cool the sample. Once grown,
CNTs were treated with ozone to improve silicon deposition. ${ }^{16}$ Gas-phase ozonation oxidizes the CNTs, which primes and increases the number of nucleation sites on the tubes and facilitates conformal growth of silica along the CNT. To ozonate the CNTs, the $\mathrm{O}_{3}$ gaseous reagent is passed over the forest with an Atlas 30 ozone generator (Absolute Ozone, Edmonton, Alberta, Canada) at an $\mathrm{O}_{2}$ flow rate of $6.7 \times 10^{-6}$ $\mathrm{m}^{3} \mathrm{~s}^{-1}$ with the current set at $45 \%$, producing approximately $4.4 \mathrm{~g} \mathrm{~h}^{-1}$ of ozone. CNT samples were placed in a $2.54-\mathrm{cm}-\mathrm{o} . \mathrm{d}$. fused-silica tube, purged for $1 \mathrm{~min}$ with oxygen $\left(\mathrm{O}_{2}\right)$, then exposed to the ozone flow for $45 \mathrm{~min}$, before finally being purged again for 1 min under an $\mathrm{O}_{2}$ flow and then removed. Sample scanning electron microscopy (SEM) images of the CNT template are shown in the Supporting Information.

After CNT growth to the desired height and ozone treatment, CNTs were coated in silicon using LPCVD (Figure 1b). Samples were placed in a sealed furnace tube and evacuated to $2 \times 10^{-4}$ Torr. The remaining air in the furnace was purged from the tube by flowing nitrogen $\left(\mathrm{N}_{2}\right)$ for $30 \mathrm{~s}$ to prevent the combustion of CNTs that would occur in air at high temperatures. The $\mathrm{N}_{2}$ flow rate was slowly reduced and then held constant as the pressure returned to $2 \times 10^{-4}$ Torr. The furnace was then heated to $535{ }^{\circ} \mathrm{C}$, and the $\mathrm{N}_{2}$ flow was turned off and replaced with the same flow rate of silane $\left(\mathrm{H}_{4} \mathrm{Si}\right)$ for $15 \mathrm{~min}$, keeping the pressure at $200 \mathrm{mT}$ Torr. The silane flow was then turned off, and the temperature was cooled to ambient. When the temperature dropped below 150 ${ }^{\circ} \mathrm{C}$, the system was flushed with $\mathrm{N}_{2}$ for $1 \mathrm{~min}$. The vacuum pump was then turned off, and $\mathrm{N}_{2}$ was introduced to the system until the pressure exceeded $500 \mathrm{mTorr}$, at which point the $\mathrm{N}_{2}$ flow was turned off and the furnace tube seal was opened to reintroduce atmospheric conditions. The resulting CNT structures were conformally coated with silicon; SEM images of conformally coated CNT structures at this intermediate step were shown in previous work and appear to be similar to that in Figure 1d shown after oxidation. ${ }^{4}$

To burn out the carbon and convert the silicon to an insulating silicon oxide, the films were placed in a furnace and heated to $850{ }^{\circ} \mathrm{C}$ in ambient air for $2 \mathrm{~min}$, allowing the silicon to oxidize (Figure 1c). After cooling to room temperature, the porous silica thin films were complete for testing. Samples of 
approximately $1-4 \mathrm{~cm}^{2}$ area were used for thermal conductivity testing.

The density of the porous silica films was determined by separating the thin film from the substrate with a razor blade and weighing it. The volume of the film was determined from the base area of the growth substrate and measured height of the film. When the mass of the film was divided by its volume, the density of the porous silica film was obtained. Density measurements indicated that the porous silica film is similar to that of an insulating silica aerogel. The volume for a $2 \times 2 \mathrm{~cm}$ film grown to $15 \mu \mathrm{m}$ height was $0.006 \mathrm{~cm}^{3}$. A typical sample of this kind weighed $0.9 \mathrm{mg}$, resulting in a density of $0.15 \mathrm{~g} \mathrm{~cm}^{-3}$. For comparison, the density of silica aerogels can range from 0.001 to $0.7 \mathrm{~g} \mathrm{~cm}^{-3} .{ }^{17}$ Silicon deposition successfully infiltrated the entire depth of the CNT forest, but deposition was observed to be somewhat thicker at the top of the CNTs than at the base (Figure 1d).

The surface roughness and film height were measured with an optical profilometer (Zeta Instruments 20). Samples were scraped along a segment of the thin film to expose the substrate and measure the height disparity between the substrate and thin film. Sample thicknesses were approximately $55 \mu \mathrm{m}$ and approximately the same height as the original CNT forest before infiltration and burnout. The surface roughness was determined by interrogating an area of $71 \times 95 \mu \mathrm{m}$ (the largest available aperture area). The average arithmetic mean roughness and root-mean-square roughness of four tested films were 1.04 [standard deviation $(\mathrm{SD})=0.19$ ] and $1.33 \mu \mathrm{m}$ (SD $=0.28)$, respectively. The maximum peak height and valley height were $4.93 \mu \mathrm{m}(\mathrm{SD}=0.72)$ and $5.62 \mu \mathrm{m}(\mathrm{SD}=2.28)$, respectively. Additional specifics regarding the surface morphology, roughness characteristics, and surface imaging is provided in the Supporting Information.

As a governing parameter in the conduction of thermal energy and to quantify the porous silica's thermal insulating properties, the thermal conductivity was measured. 1D heat transfer was established, and the thermal resistance across the thin film was determined with the aid of a reference measurement. The layers of material present in the test condition and the associated thermal resistance for each layer are shown in Figure 2 (with the thermal resistance associated with the porous silica film highlighted in blue; Figure 2d).

To heat the silicon substrate to steady state and establish 1D heat transfer, samples were placed on a $5.1 \times 2.7 \times 1.3 \mathrm{~cm}$ copper block to act as a large, isothermal substrate that was heated by an attached thin-film heater. Four T-type thermocouples were placed in the copper block $1.3 \mathrm{~cm}$ from each side edge and 0.3 and $0.8 \mathrm{~cm}$ from the top surface, embedded half-way into the block to ensure isothermal conditions in the copper. Thermal insulating foam encased the sides and bottom of the copper block and heater to reduce heat loss and further ensure isothermal conditions. Test samples were placed on top of the isothermal copper block and heated via conduction. Accompanying temperature measurements of the copper block at steady state for each test confirmed temperature uniformity, as noted in the Supporting Information.

During testing, a reference sample and one or more test samples were placed on the heated copper substrate. The copper substrate was painted black in regions where the test samples were not located (Figure 2). The black paint (emissivity $\varepsilon=0.97$; Krylon Ultra Flat Black) enabled use of an IR camera (FLIR SC6103) to measure surface temper- (a)

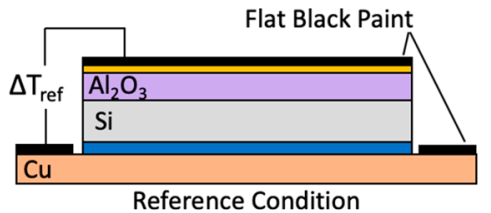

(b)

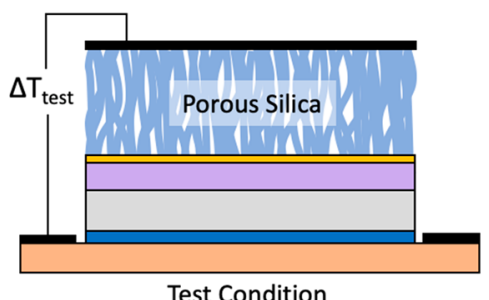

(c)

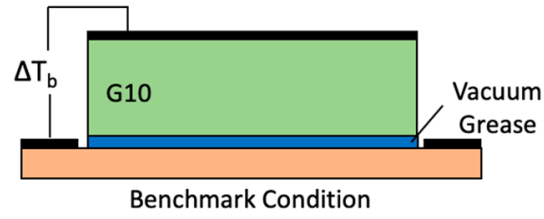

(d) $i^{T}$

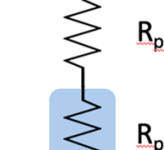

q"

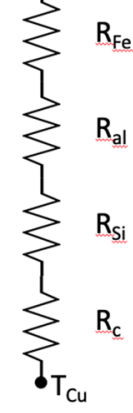

Figure 2. (a) Schematic of the reference conditions used to determine the thermal resistance of all layers except the porous silica film. (b) Schematic of the test conditions used to determine the thermal resistance of the porous silica film. (c) Schematic of the benchmark conditions using a material of known thermal conductivity (G10) to confirm the measurement method. (d) Resistance network for the material stack for the test conditions, including the porous silica film.

atures. The top of each test sample (or reference/benchmark sample) was also painted black in the same manner in order to determine the temperature difference across test samples $\left(\Delta T_{\text {test }}\right)$ using the IR camera during heating. Each film was sprayed twice by hand with a smooth, even pass. Each pass lasted approximately $0.5 \mathrm{~s}$ over the $1 \mathrm{~cm}$ length of the film. Control and benchmark samples were prepared in the same way. The surface temperature for each test was determined using an average over the top surface of each sample (see an explanation in the Supporting Information).

The isothermal copper substrate with reference and test samples were placed in a vacuum chamber (measuring $70 \mathrm{~cm}$ in diameter and $76.2 \mathrm{~cm}$ in length) and evacuated to a pressure of less than $4 \times 10^{-5}$ Torr in order to neglect convective heat transfer from the surface. ${ }^{18}$ The IR camera was located exterior to the vacuum chamber with a direct line of sight to the sample surfaces through a $7.5-\mathrm{cm}$-diameter sapphire window. The window had a band transmissivity of $0.81-0.85$ for source temperatures between 323 and $423 \mathrm{~K}$ in the spectral band of 3-5 $\mu \mathrm{m}$, corresponding to the wavelength range of measurement by the IR camera. ${ }^{19}$ A transmissivity of 0.83 was used for IR measurements through the sapphire window, and the impact of the transmissivity variation on the IR measurement of the sample was accounted for by incorporating possible transmissivity variation with temperature into the IR measurement uncertainty (see the Supporting Information).

Because the test and reference samples were thin $(<600$ $\mu \mathrm{m})$, heat loss from the sides of the samples was neglected, resulting in $1 \mathrm{D}$ conduction heat transfer through the sample thickness and heat loss from the samples radiated to the vacuum chamber walls at ambient temperature. The thermal resistances in the stack are identified by each layer comprising the sample (Figure 2), namely, silicon substrate $\left(R_{\mathrm{Si}}\right)$, alumina diffusion barrier $\left(R_{\mathrm{al}}\right)$, iron catalyst $\left(R_{\mathrm{Fe}}\right)$, porous silica $\left(R_{\mathrm{ps}}\right)$, and black paint $\left(R_{\mathrm{p}}\right)$. The conduction resistance for these 
layers can each be calculated using $R=L / k A$, assuming $1 \mathrm{D}$, steady-state conduction and constant properties (where $L$ is the thickness, $k$ is the thermal conductivity, and $A$ is the area of each layer). An additional contact resistance $\left(R_{\mathrm{c}}\right)$ is present and includes a thin layer of vacuum grease used for good contact between the substrate and sample.

The reference test, which excludes the resistance associated with the porous silica film, can be used to determine a composite resistance associated with all other layers and the contact resistance combined, creating $R_{\text {comp }}$ in eq 1 .

$$
R_{\text {comp }}=R_{\mathrm{c}}+R_{\mathrm{Si}}+R_{\mathrm{al}}+R_{\mathrm{Fe}}+R_{\mathrm{p}}
$$

This composite resistance can be determined by measuring the temperature difference across the reference sample $\left(\Delta T_{\text {ref }}\right)$ and calculating the radiative heat rate, leaving the surface of the reference sample, as given in eq 2 .

$$
q_{\text {comp }}=\frac{\Delta T_{\text {ref }}}{R_{\text {comp }}}
$$

This heat rate $\left(q_{\text {comp }}\right)$ is equivalent to the net radiative heattransfer rate $\left(q_{\mathrm{rad}}\right)$ shown in eq 3 because the heated surfaces are small relative to the isothermal vacuum chamber ${ }^{20}$

$$
q_{\mathrm{rad}}=\varepsilon \sigma A\left(T_{\mathrm{t}}^{4}-T_{\text {surr }}{ }^{4}\right)
$$

where $T_{\text {surr }}=296.15 \mathrm{~K}$ (as measured by a thermocouple placed on the aluminum chamber wall), $\varepsilon$ is the emissivity, $A$ is the surface area, and $\sigma$ is the Stefan-Boltzmann constant $(5.67 \times$ $\left.10^{-8} \mathrm{~W} \mathrm{~m}^{-2} \mathrm{~K}^{-4}\right)$. With $q_{\text {comp }}$ and $\Delta T_{\text {ref }}$ obtained, the composite resistance is readily calculated and used to determine the resistance to heat transfer across the layers of material in the test conditions excluding the resistance associated with the porous silica film.

A measurement similar to that outlined above for the reference conditions is performed simultaneously for test surfaces that include a porous silica film, introducing an additional layer of resistance. With $R_{\text {comp }}$ known from measurements associated with the reference conditions, the rate of radiative heat loss (calculated using a new surface temperature $T_{1}$ for the test conditions) can be equated to the measured $\Delta T_{\text {test }}$ divided by the sum of the composite resistance and the resistance associated with the porous silica film, yielding eq 4 .

$$
\varepsilon \sigma A\left(T_{\mathrm{t}}^{4}-T_{\mathrm{surr}}{ }^{4}\right)=\frac{\Delta T_{\text {test }}}{R_{\mathrm{comp}}+R_{\mathrm{ps}}}=\frac{\Delta T_{\text {test }}}{\frac{L_{\text {comp }}}{k_{\mathrm{comp}} A}+\frac{L_{\mathrm{ps}}}{k_{\mathrm{ps}} A}}
$$

The only unknown in eq 4 is the cross-plane thermal conductivity of the porous silica film $\left(k_{\mathrm{ps}}\right)$, which can now be obtained by inserting the known expression for the thermal conductivity of the composite, yielding eq 5 .

$T_{\mathrm{t}}$ and $T_{\text {comp }}$ are the top surface temperatures, read from the thermal camera, of the porous silica and reference composite sample, respectively.

$$
k_{\mathrm{ps}}=\frac{L_{\mathrm{ps}}}{\frac{\Delta T_{\text {test }}}{\varepsilon \sigma\left(T_{\mathrm{t}}^{4}-T_{\text {surr }}{ }^{4}\right)}-\frac{\Delta T_{\text {ref }}}{\varepsilon \sigma\left(T_{\text {comp }}{ }^{4}-T_{\text {surr }}{ }^{4}\right)}}
$$

The copper substrate temperature was increased using a thinfilm heater with wire leads passing through a vacuum feedthrough until a desired temperature was reached. Each test was allowed to reach steady-state behavior, defined as less than a $0.5 \mathrm{~K}$ temperature change in the copper block over 10 min. Repeat testing at several copper block temperatures was performed, with steady-state behavior reached for each condition. Higher copper block temperatures resulted in larger $\Delta T_{\text {test }}$ values and greater confidence in the temperature differences measured.

In order to verify the measurement approach for obtaining the thermal conductivity, benchmark samples of Garolite fiberglass laminate (G10, McMaster-Carr) were cut from sheets of thickness of $0.79,1.59$, and $3.18 \mathrm{~mm}$. The $0.79-\mathrm{cm}$ thick samples were used for reference condition measurements with the 1.59 and $3.18 \mathrm{~mm}$ samples used as test condition samples following the approach outlined above for determining thermal conductivity for the porous silica film. This approach of using both a thinner reference condition and a thicker test condition with G10 eliminated the requirement of obtaining the contact resistance. In this manner, the thermal conductivity for G10 could be determined and compared with a published thermal conductivity value, thereby validating the measurement approach. Further, the thermal resistance of G10 in the thicknesses selected above $\left(R_{\mathrm{t}}^{\prime \prime}=2.6 \times 10^{-3} \mathrm{~m}^{2} \mathrm{~K} \mathrm{~W}^{-1}\right)$ was on the same order as that anticipated from the porous silica layer based on calculations using the thermal conductivity of silica aerogel and a film thickness of $55 \mu \mathrm{m}$.

The measured thermal conductivity for G10 averaged 0.31 and $0.25 \mathrm{~W} \mathrm{~m}^{-1} \mathrm{~K}^{-1}$ for the 1.59- and 3.18-mm-thick samples, respectively, over the temperature range of 391-434 K. Published values of the thermal conductivity for G10 are approximately $0.29 \mathrm{~W} \mathrm{~m}^{-1} \mathrm{~K}^{-1}$. ${ }^{21}$ Using this value as the correct thermal conductivity, the current measurement approach for the two thicknesses provided results with errors of $7 \%$ and $14 \%$. While additional refinements could be made to the measurement method, the good agreement between the measured and published thermal conductivity for G10 yields confidence in using the measurement method for obtaining reasonable thermal conductivity values for the porous silica films.

Thermal characterization of the porous silica films was performed in a manner similar to the benchmark tests using G10. On the basis of the surface temperature measurements of the reference condition and a test sample with a porous silica film, the thermal conductivity was determined using eq 5 . Thermal conductivities for two porous silica films are shown in Figure 3 (PS1/PS2), obtained using two reference samples (REF1/REF2). The resulting four measurements obtained from a combination of different samples and references vary by $\lesssim 15 \%$ relative to the mean at a given substrate temperature with a mean of $0.062 \mathrm{~W} \mathrm{~m}^{-1} \mathrm{~K}^{-1}$ over the range of $378-422 \mathrm{~K}$. The thermal conductivity of the porous silica films seems to increase only slightly with increasing copper substrate temperature over the range of temperatures tested, with a range of thermal conductivity values of $0.054-0.071 \mathrm{~W} \mathrm{~m}^{-1}$ $\mathrm{K}^{-1}$ over all measurements. Table 1 shows a comparison of the density and thermal conductivities for several related materials, including the silica aerogel and porous silica film. The results indicate that the thermal conductivity obtained for the porous silica films created and characterized using the methods proposed here are consistent with silica aerogels, while also offering a method to integration on a silicon platform.

The uncertainty in the measured thermal conductivity was calculated by using the partial derivative of each variable in eq 5 and the associated uncertainty of that variable. Uncertainty values and calculation methodology are provided in the 


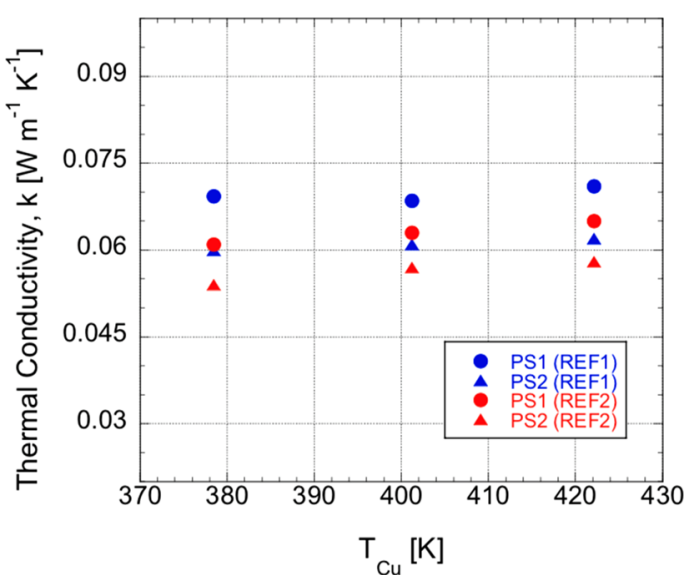

Figure 3. Thermal conductivity results of two porous silica films (PS1/PS2) when compared to two separate control samples (REF1/ REF2). A condition of "PS1 (REF1)" indicates a result for porous silica film 1 (PS1) relative to reference sample 1 (REF1).

Table 1. Density and Thermal Conductivity of Several Comparable or Constituent Insulating Materials, ${ }^{17,22}$ Including the Porous Silica Film of the Current Work

\begin{tabular}{lll} 
& \multicolumn{1}{c}{$\begin{array}{c}\text { density } \\
\left(\mathrm{g} \mathrm{cm}^{-3}\right)\end{array}$} & $\begin{array}{c}\text { thermal conductivity } \\
\left(\mathrm{W} \mathrm{m} \mathrm{K}^{-1}\right)\end{array}$ \\
air & 0.001 & 0.024 \\
G10 & 1.800 & 0.290 \\
silicon & 2.329 & 150.0 \\
silicon dioxide & 2.196 & 1.400 \\
silica aerogel & $0.001-0.700$ & $0.004-0.030$ \\
porous silica (current & 0.150 & $0.054-0.071$ \\
work) & &
\end{tabular}

Supporting Information. For these conditions, the total uncertainty was determined to be $0.0075 \mathrm{~W} \mathrm{~m}^{-1} \mathrm{~K}^{-1}$.

Experiments for the porous silica film were performed in a vacuum, resulting in a mean thermal conductivity of $0.062 \mathrm{~W}$ $\mathrm{m}^{-1} \mathrm{~K}^{-1}$. The thermal conductivity of air is $0.024 \mathrm{~W} \mathrm{~m}^{-1}$ $\mathrm{K}^{-1}$. ${ }^{23}$ As an example, Maxwell's formula for the effective thermal conductivity of a porous medium indicates the potential for a $\sim 25 \%$ increase in the thermal conductivity when including the influence of the interstitial fluid (air), assuming a $\sim 93 \%$ porosity material. ${ }^{24}$ However, the Knudsen effect, which occurs when a material's pore diameter is less than the mean-free path of the gas molecules, may reduce the overall thermal conductivity. ${ }^{25}$ In air, this occurs in pores of 40 $\mathrm{nm}$ diameter and smaller and can reduce the thermal conductivity to less than $0.004 \mathrm{~W} \mathrm{~m}^{-1} \mathrm{~K}^{-1}$. 25 Additionally, it should be noted that this thermal conductivity measurement method yields an average value over the film thickness at the micron scale for an inhomogeneous material at the nanoscale. It is possible that changes in the thermal conductivity may also be observed for different porous silica thicknesses if the plasma-enhanced CVD coating thickness at the top and bottom of the film is appreciably different or if burnout of the carbon varies for different thicknesses.

This work reports on a fabrication method for porous silica films and determines the thermal conductivity of these films, created using CNTs as a scaffold. The porous silica film may be used in MEMS/NEMS structures because it has excellent thermally insulating properties, with a thermal conductivity of approximately $0.062 \mathrm{~W} \mathrm{~m}^{-1} \mathrm{~K}^{-1}$ in the range of $378-422 \mathrm{~K}$.
This thermal conductivity value is in the range of other silica aerogels and has a very low density of $0.15 \mathrm{~g} \mathrm{~cm}^{-3}$. The film is also relatively smooth and flat, with an average arithmetic mean roughness of $1.04 \mu \mathrm{m}$. The porous silica films demonstrate the ability for CNTs to be used as a structural template for the fabrication of micro/nanostructures. Future work includes the use of alternative coating materials besides silicon/silica, opening interesting possibilities in material creation.

\section{ASSOCIATED CONTENT}

\section{Supporting Information}

The Supporting Information is available free of charge at https://pubs.acs.org/doi/10.1021/acsanm.0c00596.

Images of the CNT template, details on the surface roughness/morphology, results from transmission electron microscopy studies, details of the temperature measurements, and uncertainty analysis (PDF)

\section{AUTHOR INFORMATION}

\section{Corresponding Author}

Brian D. Iverson - Brigham Young University, Provo, Utah 84602, United States; orcid.org/0000-0002-4592-3728; Email: bdiverson@byu.edu

\section{Authors \\ Derric B. Syme - Brigham Young University, Provo, Utah 84602, United States \\ Jason M. Lund - Brigham Young University, Provo, Utah 84602, United States \\ Brian D. Jensen - Brigham Young University, Provo, Utah 84602, United States \\ Robert C. Davis - Brigham Young University, Provo, Utah 84602, United States; 이이이.0rg/0000-0002-6165-4396 \\ Richard R. Vanfleet - Brigham Young University, Provo, Utah 84602, United States; 10 orcid.org/0000-0002-2224-6090}

Complete contact information is available at:

https://pubs.acs.org/10.1021/acsanm.0c00596

\section{Notes}

The authors declare no competing financial interest.

\section{ACKNOWLEDGMENTS}

This material is based on work supported by Brigham Young University.

\section{REFERENCES}

(1) Ago, H.; Petritsch, K.; Shaffer, M. S. P.; Windle, A. H.; Friend, R. H. Composites of Carbon Nanotubes and Conjugated Polymers for Photovoltaic Devices. Adv. Mater. 1999, 11 (15), 1281-1285.

(2) Kaempgen, M.; Chan, C. K.; Ma, J.; Cui, Y.; Gruner, G. Printable Thin Film Supercapacitors Using Single-Walled Carbon Nanotubes. Nano Lett. 2009, 9 (5), 1872-1876.

(3) Hutchison, D. N.; Morrill, N. B.; Aten, Q.; Turner, B. W.; Jensen, B. D.; Howell, L. L.; Vanfleet, R. R.; Davis, R. C. Carbon Nanotubes as a Framework for High-Aspect-Ratio MEMS Fabrication. J. Microelectromech. Syst. 2010, 19 (1), 75-82.

(4) Song, J.; Jensen, D. S.; Hutchison, D. N.; Turner, B.; Wood, T.; Dadson, A.; Vail, M. A.; Linford, M. R.; Vanfleet, R. R.; Davis, R. C. Carbon-Nanotube-Templated Microfabrication of Porous SiliconCarbon Materials with Application to Chemical Separations. Adv. Funct. Mater. 2011, 21 (6), 1132-1139. 
(5) Chandrashekar, A.; Ramachandran, S.; Pollack, G.; Lee, J. S.; Lee, G. S.; Overzet, L. Forming Carbon Nanotube Composites by Directly Coating Forests with Inorganic Materials Using Low Pressure Chemical Vapor Deposition. Thin Solid Films 2008, 517 (2), 525530.

(6) Jensen, D. S.; Kanyal, S. S.; Gupta, V.; Vail, M. A.; Dadson, A. E.; Engelhard, M.; Vanfleet, R.; Davis, R. C.; Linford, M. R. Stable, Microfabricated Thin Layer Chromatography Plates without Volume Distortion on Patterned, Carbon and Al2O3-Primed Carbon Nanotube Forests. Journal of Chromatography A 2012, 1257, 195203.

(7) Harris, K. D.; Vick, D.; Gonzalez, E. J.; Smy, T.; Robbie, K.; Brett, M. J. Porous Thin Films for Thermal Barrier Coatings. Surf. Coat. Technol. 2001, 138 (2), 185-191.

(8) Gauthier, B. M.; Bakrania, S. D.; Anderson, A. M.; Carroll, M. K. A Fast Supercritical Extraction Technique for Aerogel Fabrication. J. Non-Cryst. Solids 2004, 350, 238-243.

(9) Huang, Z.; Ruan, X. Nanoparticle Embedded Double-Layer Coating for Daytime Radiative Cooling. Int. J. Heat Mass Transfer 2017, 104, 890-896.

(10) Bao, H.; Yan, C.; Wang, B.; Fang, X.; Zhao, C. Y.; Ruan, X. Double-Layer Nanoparticle-Based Coatings for Efficient Terrestrial Radiative Cooling. Sol. Energy Mater. Sol. Cells 2017, 168, 78-84.

(11) Marszewski, M.; King, S. C.; Yan, Y.; Galy, T.; Li, M.; Dashti, A.; Butts, D. M.; Kang, J. S.; McNeil, P. E.; Lan, E.; Dunn, B.; Hu, Y.; Tolbert, S. H.; Pilon, L. Thick Transparent Nanoparticle-Based Mesoporous Silica Monolithic Slabs for Thermally Insulating Window Materials. ACS Applied Nano Materials 2019, 2 (7), 4547-4555.

(12) Rastrello, F.; Placidi, P.; Scorzoni, A.; Cozzani, E.; Messina, M.; Elmi, I.; Zampolli, S.; Cardinali, G. C. Thermal Conductivity Detector for Gas Chromatography: Very Wide Gain Range Acquisition System and Experimental Measurements. IEEE Trans. Instrum. Meas. 2013, 62 (5), 974-981.

(13) Cruz, D.; Chang, J.; Showalter, S.; Gelbard, F.; Manginell, R.; Blain, M. Microfabricated Thermal Conductivity Detector for the Micro-Chemlab. Sens. Actuators, B 2007, 121 (2), 414-422.

(14) Wu, Y. E.; Chen, K.; Chen, C. W.; Hsu, K. H. Fabrication and Characterization of Thermal Conductivity Detectors (Tcds) of Different Flow Channel and Heater Designs. Sens. Actuators, A 2002, 100, 37-45.

(15) Van Hoof, C.; De Moor, P. Polysige Uncooled Microbolometers for Thermal Ir Detection. In Handbook of Infra-Red Detection Technologies; Henini, M., Razeghi, M., Eds.; Elsevier Science: Amsterdam, The Netherlands, 2002; pp 449-479.

(16) Jensen, D.; Kanyal, S.; Madaan, N.; Miles, A. J.; Davis, R.; Vanfleet, R.; Vail, M. A.; Dadson, A.; Linford, M. Ozone Priming of Patterned Carbon Nanotube Forests for Subsequent Atomic Layer Deposition-Like Deposition of $\mathrm{SiO} 2$ for the Preparation of Microfabricated Thin Layer Chromatography Plates. J. Vac. Sci. Technol., B: Nanotechnol. Microelectron.: Mater., Process., Meas., Phenom. 2013, 31 (3), 031803-1.

(17) Soleimani Dorcheh, A.; Abbasi, M. H. Silica Aerogel; Synthesis, Properties and Characterization. J. Mater. Process. Technol. 2008, 199 (1), 10-26.

(18) Guy, W. W.; Ellis, W. E. Vacuum Chamber Heat-Transmission Analysis; National Aeronautics and Space Administration: Houston, TX, 1967; pp 1-10; NASA-TM-X-1355.

(19) Mulford, R. B.; Dwivedi, V. H.; Jones, M. R.; Iverson, B. D. Control of Net Radiative Heat Transfer with a Variable-Emissivity Accordion Tessellation. J. Heat Transfer 2019, 141, 032702.

(20) Bergman, T. L.; Lavine, A. S.; Incropera, F. P.; DeWitt, D. P. Fundamentals of Heat and Mass Transfer, 7th ed.; John Wiley and Sons, Inc., 2011; p 10.

(21) Ho, H.-N.; Jones, L. A. Contribution of Thermal Cues to Material Discrimination and Localization. Perception \& Psychophysics 2006, 68 (1), 118-128.

(22) Lide, D. R. CRC Handbook of Chemisty and Physics, 86th ed.; CRC Press (an imprint of Taylor and Francis Group): Boca Raton, FL, 2005.
(23) Young, H. D.; Sears, F. W. University Physics; Addison-Wesley Pub. Co.: Reading, MA, 1992.

(24) Aichlmayr, H. T.; Kulacki, F. A. The Effective Thermal Conductivity of Saturated Porous Media. Adv. Heat Transfer 2006, 39 (C), 377-460.

(25) Jelle, B. P.; Gustavsen, A.; Baetens, R. The Path to the High Performance Thermal Building Insulation Materials and Solutions of Tomorrow. J. Build. Phys. 2010, 34 (2), 99-123. 